\title{
OPEN Solidified floating organic droplet microextraction coupled with HPLC for rapid determination of trans, trans muconic acid in benzene biomonitoring
}

\begin{abstract}
Fatemeh Dehghani ${ }^{1}$, Fariborz Omidi ${ }^{2}$, Omidreza Heravizadeh ${ }^{3,4}$ \& Saeed Yousefinejad ${ }^{5 凶}$
Benzene is one of the carcinogenic compounds in the work environments. Exposure assessment of benzene through biological monitoring is an acceptable way to accurately measure the real exposure in order to conducting the health risk assessment, but it is always complicated, laborious, time consuming and costly process. A new sensitive, simple, fast and environmental friendly method was developed for the determination of urinary metabolite of benzene, trans trans muconic acid ( $t, t-M A)$ by dispersive liquid-liquid micro extraction based on solidification of floating organic droplet coupled with high-performance liquid chromatography with ultra violet detector. Central composite design methodology was utilized to evaluate the effective factors on the extraction output of the target metabolite. The calibration curve was plotted in the concentration ranges of $0.02-5 \mu \mathrm{g} \mathrm{mL}^{-1}$. The precision and accuracy of the method were assayed via the relative standard deviation (RSD\%) and relative recovery (RR\%) using spiked samples with three replications. The RR\% and RSD\% of the optimized method were $86.9-91.3 \%$ and $4.3-6.3 \%$ respectively. The limit of detection (LOD) of the method was $0.006 \mu \mathrm{g} \mathrm{mL}^{-1}$. The level of $\mathrm{t}$, $\mathrm{t}-\mathrm{MA}$ in real samples was ranged from 0.54 to $1.64 \mathrm{mg} / \mathrm{g}$ creatinine. We demonstrated that $t, t-M A$ can be extracted and determined by an inexpensive, simple and fast method.
\end{abstract}

Nowadays, organic solvents are extensively used in various processes because of their unique characters. Benzene, a well-known organic solvent, is applied to synthesize new material in different processes such as petrochemical, paint, adhesive process, rubber, and plastic ${ }^{1}$. Breathing and skin contact are regarded as the major paths of exposure to benzene ${ }^{2}$. The carcinogenicity of benzene (class I carcinogen) has been confirmed by the US Environmental Protection Agency (EPA) and International Agency for Research on Cancer (IARC) ${ }^{3,4}$. Many adverse health problems may be created through benzene intake. The effect of benzene on the hematopoietic organ is one of the main adverse health effects that has long been considered. Suppression of blood factors such as hemoglobin and white blood cells has been reported in people exposed to benzene ${ }^{5,6}$. Moreover, long-term exposure may suppress the immune system and reduce the number of lymphocytes ${ }^{7}$.

There are two ways to accurately determine the level of exposure to pollutants: air sampling and biological monitoring. Benzene could enter the body via inhalation, gastrointestinal system and skin contact ${ }^{8}$. Therefore, biological monitoring is necessary for precise determination of real exposure to benzene. During metabolism process, benzene is metabolized to different ring-opened and hydroxylated compounds such as trans, transmuconic acid (t,t-MA), phenol, catechol and S-phenylmercapturic acid ${ }^{9,10}$. Phenol and catechol metabolites were associated with high concentration of benzene exposure (higher than $10 \mathrm{ppm}$ ). However, in low levels of benzene (lower than $1 \mathrm{ppm}$ ), no association was found between urinary levels of phenol and catechol compounds ${ }^{11}$. It

\footnotetext{
${ }^{1}$ Student research committee, Shiraz University of Medical Sciences, Shiraz, Iran. ${ }^{2}$ Research Center for Environmental Determinants of Health (RCEDH), Health Institute, Kermanshah University of Medical Sciences, Kermanshah, Iran. ${ }^{3}$ Division of Metabolomics, Medical Institute of Bioregulation, Kyushu University, Fukuoka 812-8582, Japan. ${ }^{4}$ Department of System Life Sciences, Graduate School of Systems Life Sciences, Kyushu University, Fukuoka 819-0395, Japan. ${ }^{5}$ Research Center for Health Sciences, Institute of Health, Department of Occupational Health Engineering, School of Health, Shiraz University of Medical Sciences, 71645-111 Shiraz, Iran. ${ }^{\circledR}$ email: yousefisa@sums.ac.ir
} 


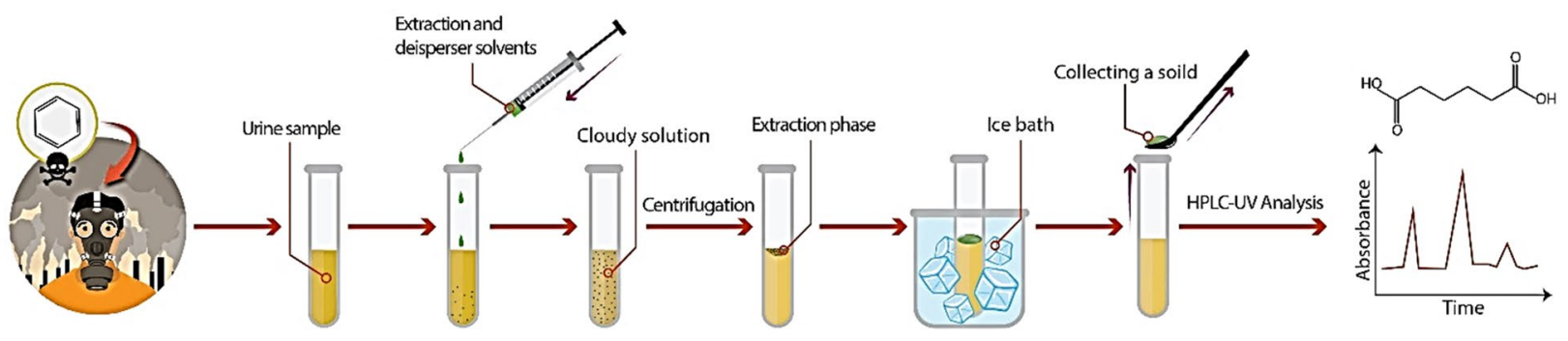

Figure 1. A schematic diagram of the utilized DLLME-SDOD procedure.

has been found that there is a good correlation between urinary t,t-MA and concentration of benzene in air and blood in low levels of benzene exposure ${ }^{12,13}$. Furthermore, the American Conference of Governmental Industrial Hygienists (ACGIH) has introduced t,t-MA as a urinary biomarker of benzene exposure ${ }^{14}$.

Oxidation is the first step of benzene metabolism which produces benzene oxide. Under the influence of the metabolism processes, benzene oxide undergoes various fates. As an alternative way during the metabolism process, benzene ring may be opened in the benzene oxide or oxepin step via the reactive intermediate muconaldehyde. By oxidizing the trans, trans-mucondialdehyde, t,t-MA is produced ${ }^{15}$.

Although monitoring of biological media is an acceptable way to accurately measure the real exposure to the compounds, it is always complicated, laborious, time consuming and costly process ${ }^{16}$. The complexity of the biological fluids and also low amounts of the metabolites are the major barriers for analyzing the biomarkers in theses media. Sample preparation is a good solution to conquer these problems.

Up to now, various modern, high-throughput, miniaturized sample preparation techniques coupled with analytical instruments have been introduced for trace monitoring of $t, t-M A$ in urine samples ${ }^{17-19}$. Due to low organic solvent consumption and high preconcentration factor, dispersive liquid-liquid microextraction (DLLME) and dispersive solid-phase microextraction (SPME) methods are among the most popular methods. The SMPE procedure requires preparation of the solid sorbent and subsequently analysis of the prepared sorbent by analytical instrument, which is time consuming and costly. The DLLME procedures are easy, rapid, and also require no extra characterization ${ }^{20,21}$. However, the use of toxic solvents (solvents used as extractant and disperser) is the main drawback of this method. Halogenated hydrocarbons are an example of these solvents, which are toxic and heavier than water ${ }^{22,23}$. As an attempt to solve these limitations, DLLME using a floating organic droplet (DLLME-SFOD) has been introduced with remarkable advantages over conventional extraction methods. The use of less toxic organic solvent, use of low organic solvent, operator safety, rapid extraction, and also environmentally friendly are some advantages of the proposed sample preparation compared to conventional DLLME ${ }^{24}$. In DLLME-SFOD technique, the density of the applied organic solvent is often lower than water, which help to be floated in the sample surface and simply collected from the sample media ${ }^{25}$. In this work, for the first time, a new DLLME-SFOD technique was optimized for the trace monitoring of t,t-MA from urine specimens. The applied organic solvent during solidification procedure has good consistency for the extraction of $t, t-M A$ with excellent recovery which was comparable with routinely applied SPE procedure in samples collected from real exposed workers with benzene. Another important point in the current work is using response surface methodology for optimization of the solidified floating organic droplet microextraction in a complex sample such as urine. Here, we tried to show the importance of multivariate-optimization (instead of one-at-a-time process), to handle a multi-factor method such as SFOD especially for a complex real media. We think the obtained wonderful results can be related to this precise optimization and considering all factors and between-factors interactions.

\section{Experimental}

Reagents and solutions. t,t-MA (analytical standard) was obtained from Sigma-Aldrich (Darmstadt, Germany). 1-undecanol (99\%), 1-dodecanol (99\%), sodium hydroxide, sodium chloride, hydrochloric acid $(\mathrm{HCl})$, acetic acid, and methanol (HPLC grade) were all provided from Merck Company (Darmstadt, Germany). Doubled distilled water was obtained from a milli-Q system (Bedford, MA, USA). Standard solutions of t,t-MA $\left(1000 \mathrm{mg} \mathrm{L}^{-1}\right)$ were prepared individually using methanol and double-distilled water at 1:4 ratio. The required working standards were daily prepared from the stock solution. The prepared stock solutions were kept at refrigerator and were freshly prepared after 10 days.

Instrumentation. Chromatographic analyses were done by a HPLC system (HPLC, Knauer,Smartline system 1000, Berlin, Germany) combined with an ultraviolet detector (Knauer, 2000). The separation of analyte was performed via a C18 analytical column (Knauer, Eurospher 100-5 C18, $150 \mathrm{~mm} \times 4.6 \mathrm{~mm}$ ). A mixture of acetic acid $1 \%$-methanol $(70 / 30 \mathrm{v} / \mathrm{v})$ with a flow rate of $1.0 \mathrm{ml} / \mathrm{min}$ was used as the mobile phase. The wavelength of UV detector was set at $274 \mathrm{~nm}$. The injection was done manually using a $20 \mu \mathrm{L}$ stainless steel loop. A Metrohm $827 \mathrm{pH}$-meter (Metrohm, Switzer-land) was used for measurement of $\mathrm{pH}$. Moreover, Hettich EBA 20 centrifuge was used for the separation of organic solvent from sample solution.

DLLME-SFO procedure. Figure 1 presents the schematic diagram of DLLME-SFOD procedure. In the proposed extraction method, a $10 \mathrm{~mL}$ of aqueous sample solution consist of $1.0 \mu \mathrm{g} \mathrm{mL}-1$ of $\mathrm{t}, \mathrm{t}$-MA was poured into a $15-\mathrm{mL}$ screw-cap glass centrifuge tube. $\mathrm{pH}$ of the solution was regulated in definite value $(\boldsymbol{A})$ by stepwise 


\begin{tabular}{|l|c|c|c|c|c|}
\hline \multirow{2}{*}{ Variables } & \multicolumn{2}{|l|}{ Level } & \multicolumn{2}{l|}{$\begin{array}{l}\text { Star } \\
\text { points }(\boldsymbol{\alpha}=\mathbf{2 . 0})\end{array}$} \\
\cline { 2 - 7 } & Low $(-\mathbf{1})$ & Central(0) & High (+1) & $-\boldsymbol{\alpha}$ & $+\boldsymbol{\alpha}$ \\
\hline A: $\mathrm{pH}$ & 3 & 5 & 7 & 1 & 9 \\
\hline B:Extractant solvent volume $(\mu \mathrm{L})$ & 30 & 40 & 50 & 20 & 60 \\
\hline C: Disperser solvent volume $(\mu \mathrm{L})$ & 100 & 200 & 300 & 0 & 400 \\
\hline D: Salt amount $(\mathrm{w} / \mathrm{v}, \%)$ & 2 & 4 & 6 & 0 & 8 \\
\hline E: Extraction time $(\mathrm{min})$ & 2 & 3 & 4 & 1 & 5 \\
\hline
\end{tabular}

Table 1. The matrix of central composite design and responses.

addition of hydrochloric acid and sodium hydroxide solution. Then, the salt amount of the solution was adjusted using required percent $(\mathrm{w} / \mathrm{v})$ of $\mathrm{NaCl}(\boldsymbol{D}, \%)$. In the next step, a mixed solution of 1-undecanol, as extractant solvent $(\boldsymbol{B}, \mu \mathrm{L})$ and the needed volume of methanol, as dispersive solvent, $(\boldsymbol{C}, \mu \mathrm{L})$ was quickly introduced into the sample solution and the resultant mixture was agitated for $30 \mathrm{~s}$ using a vortex mixer. In this step, a cloudy suspension was created because of the dispersion of tiny droplets of 1-undecanol in the sample solution and subsequently, the extraction of analyte into 1-undecanol occurred quickly. The formed emulsion was then centrifuged for $5.0 \mathrm{~min}$ at $4000 \mathrm{rpm}$. After centrifugation, the tiny droplets of extractant solvent ${ }^{1-\text { undecanol }}$ containing analyte were floated at the top of the sample solution due to the difference between the density of 1-undecanol and aqueous solution. The glass tube was then put into cold-water immersion for 5 min until the solidification of organic solvent occurred. Finally, the solidified organic droplet was put into a HPLC vial and brought to lab temperature. In lab temperature, the solidified droplet was quickly melted and then analyzed by the HPLC-UV.

Real sample collection. Metabolite-free urine specimen was obtained from a healthy male in the analytical lab. Moreover, five end-shift urine samples from exposed workers of a petrochemical company were taken for monitoring of t,t-MA. All collected urine samples were stored at $-20^{\circ} \mathrm{C}$, prior to analysis. Sampling urine sample and human participation was done in compliance with the relevant regulations and the ethical principles outlined in the Helsinki's declaration. This study was approved by the Ethics Committee of the Shiraz University of Medical Sciences.

Sample treatment. Before analysis, both blank (samples taken from unexposed healthy male) and real samples (samples taken from workers who occupationally expose to benzene) were prepared according to the following method; $10 \mathrm{~mL}$ of each sample was transferred to a conical centrifuged tube and centrifuged for $10 \mathrm{~min}$ at $4000 \mathrm{rpm}$. The supernatant liquid was then filtered via a $0.45 \mu \mathrm{m}$ filter and $5 \mathrm{~mL}$ of the obtained solution was poured to a vial. For reducing the effect of matrix, the urine sample was diluted to $10 \mathrm{~mL}$ using double distilled water. The obtained solution was then pre-concentrated using DLLME-SFOD procedure and finally analyzed by HPLC-UV.

Experimental design. Different parameters including the solution $\mathrm{pH}$, salt amount, type and volume of the disperser and extractant solvents, and extraction time affect the efficiency of the microextraction techniques. Therefore, an essential step in extraction techniques is determination of the optimum conditions of experiments. Experimental design methodology is an effective way for optimizing of the effective parameters on the extraction process. Saving time, enhancing the efficiency of the process, investigation of the interactions between parameters, and decreasing the errors with the minimum numbers of runs are some advantages of the experimental design method ${ }^{26-28}$. Response surface methodology (RSM) have been extensively utilized to link polynomial models with experimental data using different approaches, including central composite design (CCD). In this study, a CCD with five variables of $\mathrm{pH}(A)$, extractant solvent volume $(B, \mu \mathrm{L})$, disperser solvent volume $(C$, $\mu \mathrm{L})$, salt amount $(D \mathrm{w} / \mathrm{v}, \%))$, and extraction time $(\min )(E)$ at five boundary levels $(-\alpha,-1,0,+1,+\alpha)$ was used (Table 1). The total runs number $(\mathrm{N})\left(\mathrm{N}=\frac{1}{2} 2^{\mathrm{K}}+2 \mathrm{~K}+\mathrm{N}_{0}\right.$, which, $\mathrm{k}$ is introduced as the number of variables and $\mathrm{N}_{0}$ is the number of central points) was calculated to be 32 runs with central and axial points $(\alpha=2)$ (Table S1, Supplementary information). The results obtained from the CCD were fitted to the following polynomial equation:

$$
Y=\sum_{i=1}^{n} b_{i} x_{i}+\sum_{i=1}^{n} b_{i i} x_{i}^{2}+\sum_{i<j}^{n} b_{i j} x_{i} x_{j}+\varepsilon
$$

where $\mathrm{Y}$ is a predicted response, $\mathrm{n}$ is the number of parameters, $\mathrm{xi}$, $\mathrm{xj}$ are independent variables in coded units ,b0, bi, bii, bij are the regression coefficients, and $\varepsilon$ is the residual error ${ }^{29,30}$. As denoted previously, we had five independent variables $(\mathrm{i}=1,2,3,4,5)$ which is shown by $A, B, C, D, E$ as code names. Subsequently, the analysis of variance (ANOVA) was used to determine the effects of linear, quadratic and interaction regression coefficient using Design Expert 7.1.3 software (Stat-Ease Inc., Minneapolis, Minnesota, USA). The adaptability between polynomial equation and response was evaluated using determination coefficient $\left(R^{2}\right)$. The significance of the polynomial equation terms was analyzed statistically by computing $F$ value at $P<0.1$. Because of high numerical values of peak area, and to have ordered results and plots, the peak areas was normalized using the maximum 
(highest peak area) and the normalized responses was utilized for further modeling, as shown in Table S1 (Supplementary information).

\section{Results and discussion}

In this study, the DLLME-SFOD followed by HPLC-UV was optimized for the extraction and determination of $\mathrm{t}$,t-MA from urine samples.

Selection of the extractant and disperser solvents. In the DLLME-SFOD method, the choice of the suitable extractant and disperser solvents is critical to attain maximum extraction output. The extractant solvent was selected regarding some requirements such as high affinity to the analyte, low density (in compared to water), immiscible with water, high extraction output for target compound, low toxicity, compatibility with HPLC chromatographic separation, inexpensive, and low volatility. Among the mentioned requirements, density parameter is one of the most important parameters compared to others due to easy collection of the extractant solvent. Considering the above-mentioned requirements, some solvents such as 1-undecanol, 1-dodecanol and 2-dodecanol, as the most popular solvents, were candidate as the extractant solvents. Herein, because of practical ease, lowest cost and availability, 1-undecanol and 1-dodecanol, which had been introduced as the most efficient extractant solvent in previous studies ${ }^{31,32}$ were tested. The results showed that 1-undecanol was the best solvent and selected for additional examinations. Miscibility in both aqueous media and extractant solvent is the only requirement for selecting disperser solvent. In this work, acetone, acetonitrile and methanol were tested and methanol was chosen as the disperser solvent because of its ability to form a suspension with fine droplets in both media and significant potential for procedure in compare with other solvents such as acetonitrile and acetone during pre-tests.

RSM-CCD. To prevent the impact of uncontrolled variables, the order of the experimental runs, shown in supplementary material, was done randomly in the CCD matrix. According to the outputs of ANOVA analysis on the collected data, the quadratic polynomial model was suitably fitted to the obtained data. Then to provide a refined model and to remove the factors or interaction terms with not-significant $P$-value $(>0.1)$ a backward elimination variable selection was done $\mathrm{e}^{33}$ and the final findings as following equation:

$$
\begin{aligned}
\text { Peak Area }= & 364.27-32.24 \times \mathrm{A}+0.38 \times \mathrm{B}-0.53 \times \mathrm{C}-3.34 \times \mathrm{D} \\
& -149.28 \times \mathrm{E}+0.04 \times \mathrm{AC}+7.39 \times \mathrm{AE}+0.02 \times \mathrm{CD}+0.10 \times \mathrm{CE}+16.06 \times \mathrm{E}^{2} .
\end{aligned}
$$

To evaluate the significance of the above multiple linear regression (MLR) model, Fisher's statistical test (F-test) was used ${ }^{33,34}$. The F-value of the above-developed model was 27.23 and was higher than the critical F-value in required degree of freedom and shows the significance of that the model which is shown in Eq. (2). Another important criterion for confirming the validity of such MLR models, obtained from the table of experimental design, is a non-significant 'Lack of Fit (LOF). F-value' of the LOF in the current model was 0.669 and confirms that LOF was not significant, and represents the absence of pure error in the suggested MLR model.

Moreover, to evaluate the overall fitness and predictive potential of the model, the squared regression coefficients, including the calibration $\mathrm{R}^{2}\left(\mathrm{R}_{\text {cal }}^{2}\right)$, adjusted $\mathrm{R}^{2}\left(\mathrm{R}_{\text {adj }}^{2}\right)$, and $\mathrm{R}^{2}$ of prediction $\left(\mathrm{R}^{2}\right.$ pred $)$ were calculated ${ }^{35}$. As denoted in Table $2, \mathrm{R}_{\text {cal }}^{2}$ shows that the suggested CCD model covers $92.8 \%$ of data. Based on literature, the amount of $\mathrm{R}^{2}$ adj was bigger than 0.8 , which confirms its goodness of $\mathrm{fit}^{36}$. Besides, the $\mathrm{R}^{2}$ pred $(=0.807)$ was consistent with the $\mathrm{R}^{2}$ adj $(=0.894)$. The closeness of $\mathrm{R}^{2}$ pred and $\mathrm{R}^{2}$ adj with a difference lower than 0.2 is an indicator for the very good prediction ability. Another statistical metrics for measuring the Signal to Noise $(\mathrm{S} / \mathrm{N})$ ratio is the adequate precision. As it is well known in literature, a ratio greater than 4 indicates an acceptable precision ${ }^{36}$. According to the results shown in Table 2, the value of 18.54 for adequate precision indicates a suitable $\mathrm{S} / \mathrm{N}$. All of the above-mentioned metrics are indicators of suitable correlation between the included factors and interaction terms in Eq. (2) with the peak area as the response value of the extraction recovery of t,t-MA using DLLME-SFOD. To show the goodness of fit in the propped model, the plot of predicted peak area versus the obtained experimental values is represented in Fig. 2a. One of the criteria for showing the applicability domain of a multiple linear regression model is laying the residual value (difference of actual and prediction response) between the accepted range of $\pm 3 \sigma^{37}$. As shown in Fig. $2 b$, the studentized residual of the obtained model had a narrow range within $\pm 2 \sigma$ which shows the reliability of model. On the other hand, the residual value of all the runs are scattered randomly in both side of zero line which confirms the absence of systematic error ${ }^{37}$.

Optimization of effective variables using CCD. According to which was shown in Eq. (2), some interaction terms was entered in the multiparameter model, including between-factors-interactions (such as $A C$, $A E, C D$ and $\mathrm{CE}$ ) and self-interactions $\left(\mathrm{E}^{2}\right)$. The three-dimensional (3D) response surface curves were applied to present the mixed effect of factors in between-factors-interaction terms, which can provide useful information to find optimal values of the independent parameters. These curves provide important information about maximum response and possible interactions between two independent variables. Figure 3 a illustrates the simultaneous effect of $\mathrm{pH}$ of sample and disperser solvent volume on the response (peak area). In all extraction techniques in which analytes are basic or acidic, $\mathrm{pH}$ is an important parameter for extraction. To survey the influence of $\mathrm{pH}$ of sample solution on extraction of $\mathrm{t}, \mathrm{t}-\mathrm{MA}$, various designed experiments were performed. As indicated in Fig. 3a, the maximal response achieved in the $\mathrm{pH}$ of 3.0, and the peak area increased by decreasing the $\mathrm{pH}$ and disperser solvent volume. At $\mathrm{pH}$ values greater than 3.0, the response is decreased because of the fact that the ratios of the ionic to molecular forms of the target molecule can be influenced by $\mathrm{pH}$ value of sample solutions $\mathrm{s}^{38}$. Therefore, acidification of the sample is essential to achieve the highest extraction of $t, t-M A$. With increasing the 


\begin{tabular}{|c|c|c|c|c|c|c|}
\hline Source of Variation & Sum of square & $D F^{a}$ & Mean square & $F$-value ${ }^{b}$ & P-value & Importance \\
\hline Model & $15,412.27$ & 10 & 1541.23 & 27.23 & $<0.0001$ & Significant \\
\hline A & 620.32 & 1 & 620.32 & 10.96 & 0.0033 & \\
\hline$B$ & 340.71 & 1 & 340.71 & 6.02 & 0.0230 & \\
\hline$C$ & 182.91 & 1 & 182.91 & 3.23 & 0.0866 & \\
\hline$D$ & 22.37 & 1 & 22.37 & 0.40 & 0.5363 & \\
\hline$E$ & 327.69 & 1 & 327.69 & 5.79 & 0.0254 & \\
\hline$A C$ & 904.65 & 1 & 904.65 & 15.98 & 0.0007 & \\
\hline$A E$ & 3496.50 & 1 & 3496.50 & 61.78 & $<0.0001$ & \\
\hline$C D$ & 233.92 & 1 & 233.92 & 4.13 & 0.0549 & \\
\hline$C E$ & 1547.05 & 1 & 1547.05 & 27.34 & $<0.0001$ & \\
\hline$E^{2}$ & 7736.15 & 1 & 7736.15 & 136.69 & $<0.0001$ & \\
\hline Residual & 1188.51 & 21 & 56.60 & & & \\
\hline Lack of Fit & 810.18 & 16 & 50.64 & 0.67 & 0.7535 & Not significant \\
\hline Pure Error & 378.33 & 5 & 75.67 & & & \\
\hline Cor Total & $16,600.78$ & 31 & & & & \\
\hline \multicolumn{7}{|l|}{ Model statistics } \\
\hline $\mathrm{R}_{\text {cal }}^{2}$ & \multicolumn{2}{|l|}{$\mathrm{R}_{\text {Adjusted }}^{2}$} & \multicolumn{2}{|l|}{$\mathrm{R}_{\text {Pred }}^{2}$} & \multicolumn{2}{|l|}{ Adequate precision } \\
\hline 0.93 & \multicolumn{2}{|l|}{0.89} & \multicolumn{2}{|l|}{0.81} & \multicolumn{2}{|l|}{18.54} \\
\hline
\end{tabular}

Table 2. Analysis of variance (ANOVA), model statistics summery and quality of the quadratic model for the extraction of $t, t-M A .{ }^{a}$ Degree of freedom. ${ }^{b}$ Test to comparing model variance with residual variance or significance of included factors.

$\mathrm{pH}, \mathrm{t}, \mathrm{t}-\mathrm{MA}(\mathrm{pKa}=3.87)$ is converted to negative ionized species, which could reduce the agglomeration of the tiny droplets of 1-undecanol containing the migrated t,t-MA to create the floating phase. In order to assay the effect of the volume of disperser solvent, different examinations were designed using several volumes of methanol in the ranges of 100-300 $\mu \mathrm{L}$. The highest response level (peak area) was obtained using $100 \mu \mathrm{L}$ of methanol. It is because of highly solubility of 1-undecanol in methanol that generate small droplets of extractant solvent and increase the extraction output. To investigate the effect of the volume of extractant solvent, various tests were conducted using different volumes of 1-undecanol (20-60 $\mu \mathrm{L})$. The optimization process obtained $49.0 \mu \mathrm{L}$ of 1-undecanol as the best value of highest extraction efficiency. Therefore, this value was used to extract t,t-MA from the spiked or real samples.

The variation in extraction time of t,t-MA versus $\mathrm{pH}$ (Fig. 3b) shows that maximum signal of analyte was obtained after 2.0 min of extraction. The time interval between the injection of the optimum values of extraction and disperser solvents to the sample solution and centrifugation is defined as the extraction time ${ }^{39}$. The impact of extraction time was studied in the ranges of 2-4 min; the findings showed that high extraction efficiency was obtained at a short time. In DLLME-SFOD method, the equilibrium state is rapidly reached because of the high contact area between aqueous sample and extractant solvent and good dispersion of the analyte. Therefore, rapid and high mass transfer of the t,t-MA from aqueous media to the 1-undecanol is occurred.

As Fig. $3 c$ indicates, the maximum extraction of $t, t-M A$ was occurred at low concentration levels of sodium chloride and low volume of disperser solvent. In high volumes of disperser, increasing the salt can restrict the viscosity of the solution and mass transfer of the analyte. Moreover, increasing salt level and disperser solvent volume will increase the volume of floating organic phase which could decrease the enrichment factor and extraction efficiency ${ }^{31,40}$.

Figure $3 \mathrm{~d}$ indicates the interaction between extraction time and disperser volume of the sample. At the constant volume of extractant solvent, by decreasing the disperser solvent volume and the extraction time the extraction of the target was increased (Fig. 3d). Enhancing the volume of disperser solvent affects the solubility of $t, t-M A$ in the sample solution which decrease the extraction of $t, t-M A$. Moreover, following the generation of cloudy state, the extraction time is almost short due to the high contact area between aqueous phase and extractant solvent. This process facilitates the diffusion of target analyte into the extractant solvent with the lowest amount of disperser solvent. The use of small volume of organic solvent and also rapid extraction time are considered as the main advantages of the optimized method.

After confirming the validity of model, simplex optimization was used to find the optimum values of experimental conditions of the t,t-MA extraction procedure which were obtained as follow: $\mathrm{pH}$ of the sample: 3.0 , the volume of extractant solvent: $49.0 \mu \mathrm{L}$, the volume of disperser solvent: $100 \mu \mathrm{L}$, salt amount: $2.0 \mathrm{w} / \mathrm{v} \%$, and extraction time: $2.0 \mathrm{~min}$.

Matrix effects. Matrix effect was defined using the percentage of signal repression/enrichment obtained for urine samples by the proposed optimized method. In this regard, at a defined concentration level, the peak area acquired from the analysis of the fortified urine samples were compared with the relative spiked mobile phase. 

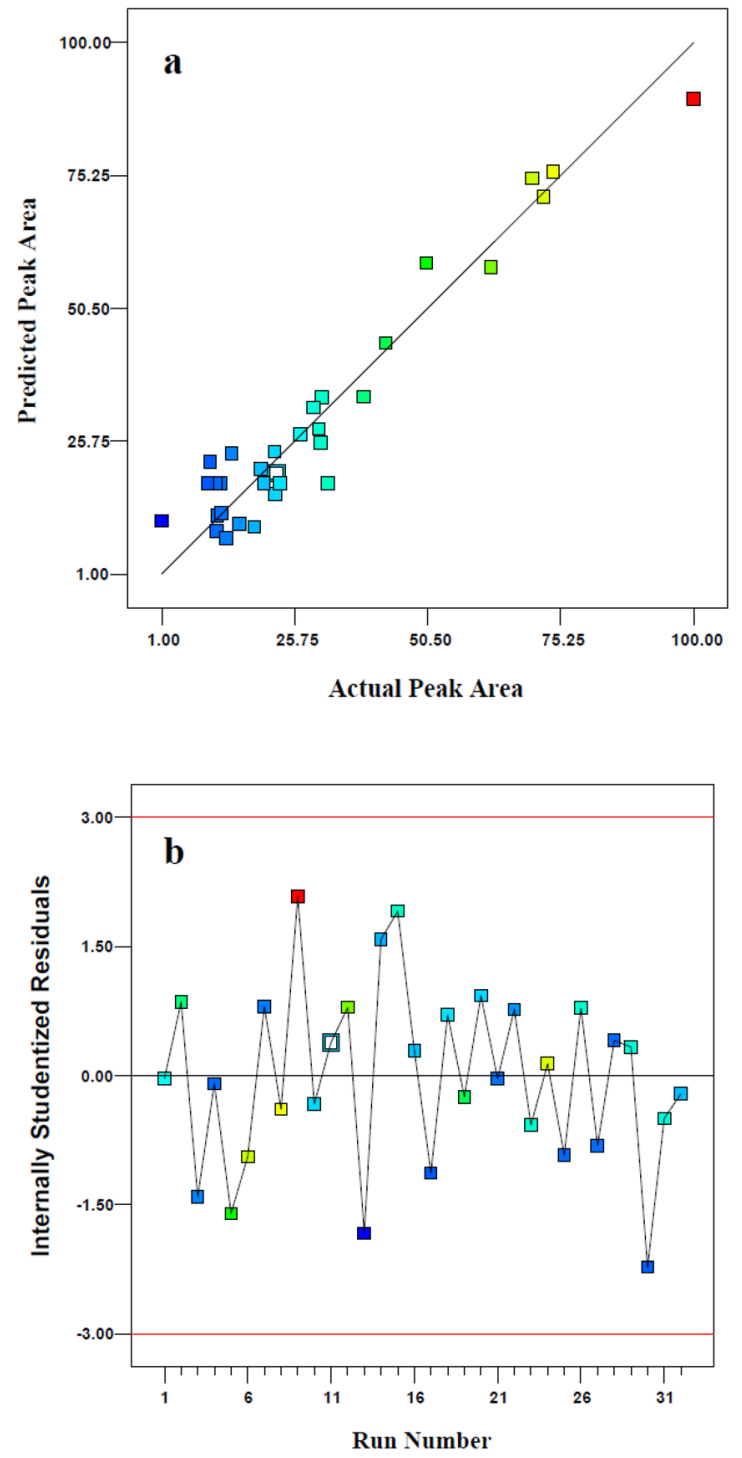

Figure 2. The internally studentized residuals vs. the performed runs (a); and the predicted value vs. actual response $(\mathbf{b})$.

Based on the obtained results, the recoveries were $91-94 \%(n=5)$. Trivial matrix effects was found when blank samples were fortified with $1.0 \mu \mathrm{g} \mathrm{mL} \mathrm{m}^{-1} \mathrm{t}, \mathrm{t}-\mathrm{MA}$.

Method validation. To assay the efficiency of the optimized method, the figures of merit such as the linear dynamic ranges (LDRs), squared correlation coefficients of the analytical curve $\left(\mathrm{R}^{2}\right)$, limit of detection (LOD), limit of quantification (LOQ), precision, and relative recovery (RR) were all examined and the obtained findings are presented in Table 3. The linearity of the optimized method was investigated by spiking seven urine specimens with increasing concentrations of t,t-MA from the LOQ to $5 \mu \mathrm{g} \mathrm{mL} \mathrm{m}^{-1}$. As demonstrated in Table 3, a suitable linearity was attained in the ranges of $0.02-5 \mu \mathrm{g} \mathrm{mL}$ with a significant correction coefficent $\left(\mathrm{R}^{2}\right.$ of 0.997$)$. The $\operatorname{LOD}(\mathrm{S} / \mathrm{N}=3)$ and LOQ $(\mathrm{S} / \mathrm{N}=10)$ were $0.006 \mu \mathrm{g} \mathrm{mL} \mathrm{L}^{-1}$ and $0.02 \mu \mathrm{g} \mathrm{mL} \mathrm{m}^{-1}$, respectively. The PF was estimated using the subsequent equation:

$$
\mathrm{PF}=\mathrm{C}_{\mathrm{ex}, \mathrm{final}} / \mathrm{C}_{\mathrm{aq}, \text { initial }}
$$

where $\mathrm{C}_{\mathrm{ex}, \text { final }}$ and $\mathrm{C}_{\mathrm{aq}}$, initial are the final and initial concentration levels of metabolite in extracting and aqueous phase, respectively. Under the optimize conditions, the PF of t,t-MA was 80. Precision study, characterized in term of RSD\% for reproducibility (inter-day precision) and repeatability (intra-day precision), was determined by spiking urine specimens purchased by an unexposed volunteer in the analytical lab. The proposed technique was used for measurement of the concentration of $\mathrm{t}, \mathrm{t}$-MA in urine sample taken from unexposed person. According to the results, no levels of $\mathrm{t}, \mathrm{t}$-MA was detected in the obtained urine sample. In the next step, the aliquots of the collected urine sample were transferred to different test vials and fortified with various concentrations of 

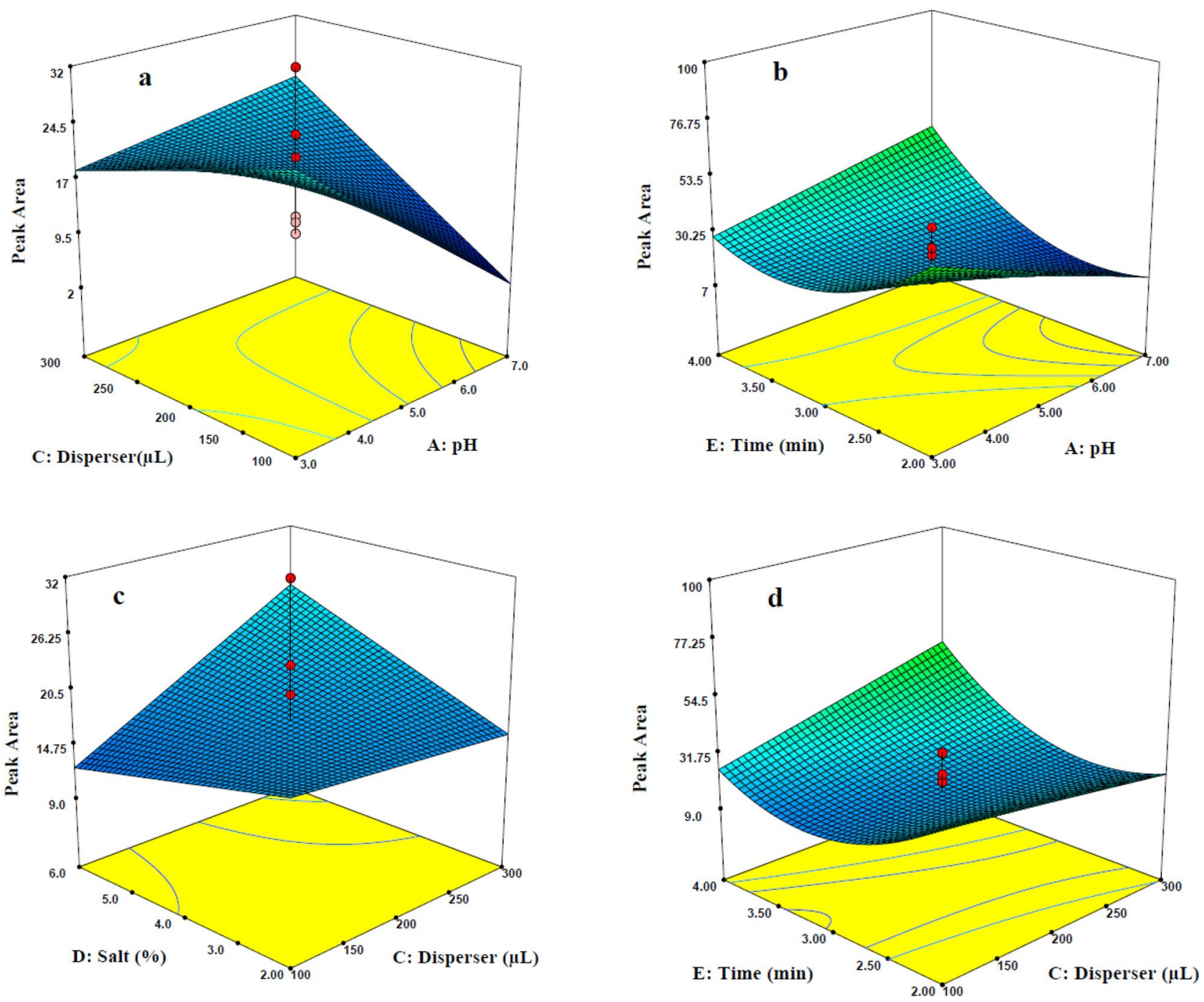

Figure 3. three dimensional response surface plots of between-factor interaction terms (volume of disperser-pH (a), time- $\mathrm{pH}(\mathbf{b})$, salt- volume of disperse (c) and time-volume of disperser (d) on the extraction of t,t-MA.

\begin{tabular}{|c|c|c|c|c|c|c|c|}
\hline \multirow[b]{2}{*}{$\begin{array}{l}\text { Correlation } \\
\text { coefficient }\left(\mathbf{r}^{2}\right)\end{array}$} & \multirow[b]{2}{*}{$\operatorname{LDR}\left(\mu \mathrm{g} \mathrm{mL} L^{-1}\right)$} & \multirow[b]{2}{*}{$\begin{array}{l}\operatorname{LOD}(\mu \mathrm{g} \\
\left.\mathrm{mL}^{-1}\right)\end{array}$} & \multirow[b]{2}{*}{$\operatorname{LOQ}\left(\mu \mathrm{g} \mathrm{mL}^{-1}\right)$} & \multirow[b]{2}{*}{$\begin{array}{l}\text { Spiked Level } \\
\left(\mu \mathrm{g} \mathrm{mL}^{-1}\right)\end{array}$} & \multirow{2}{*}{\begin{tabular}{|l|} 
Accuracy \\
Recovery (\%)
\end{tabular}} & \multicolumn{2}{|c|}{ Precision $(n=3)$} \\
\hline & & & & & & $\begin{array}{l}\text { Intra-day } \\
\text { (RSD\%) }\end{array}$ & \begin{tabular}{|l}
$\begin{array}{l}\text { Inter-day } \\
\text { (RSD\%) }\end{array}$ \\
\end{tabular} \\
\hline \multirow{3}{*}{0.997} & \multirow{3}{*}{$0.02-5$} & \multirow{3}{*}{0.006} & \multirow{3}{*}{0.02} & 0.2 & 86.9 & 5.9 & 4.8 \\
\hline & & & & 1 & 90.3 & 6.3 & 4.3 \\
\hline & & & & 2 & 91.3 & 4.3 & 3.8 \\
\hline
\end{tabular}

Table 3. Analytical characteristics of the method.

t,t-MA. The prepared fortified samples were analyzed by the optimized method. According to Table 3, the RSD\% were below 6.5 in all concentration levels, indicating a good precision achieved by this method. The proximity of the experimental findings from a developed procedure to the real amount of the target analyte is defined as the accuracy of an analytical procedure. The application of Certified Reference Materials (CRMs) is considered as an accurate way to examine the accuracy of a procedure. Since no CRM was available for the studied analyte, the trueness of the developed method was determined by the added-found procedure. To do this, the urine samples were spiked with $\mathrm{t}, \mathrm{t}-\mathrm{MA}$ analyte at three concentration levels $\left(0.2,1.0\right.$ and $\left.2.0 \mu \mathrm{g} \mathrm{mL}^{-1}\right)$ and were determined in three replicates according to the optimum conditions ( $\mathrm{pH}$ of the sample: 3.0, the volume of extractant solvent: $49.0 \mu \mathrm{L}$, the volume of disperser solvent: $100 \mu \mathrm{L}$, salt amount: $2.0 \mathrm{w} / \mathrm{v} \%$, and extraction time: $2.0 \mathrm{~min}$ ). As shown in Table 3, a good recovery obtained with the current method in the range of $86.9-91.3 \%$. 


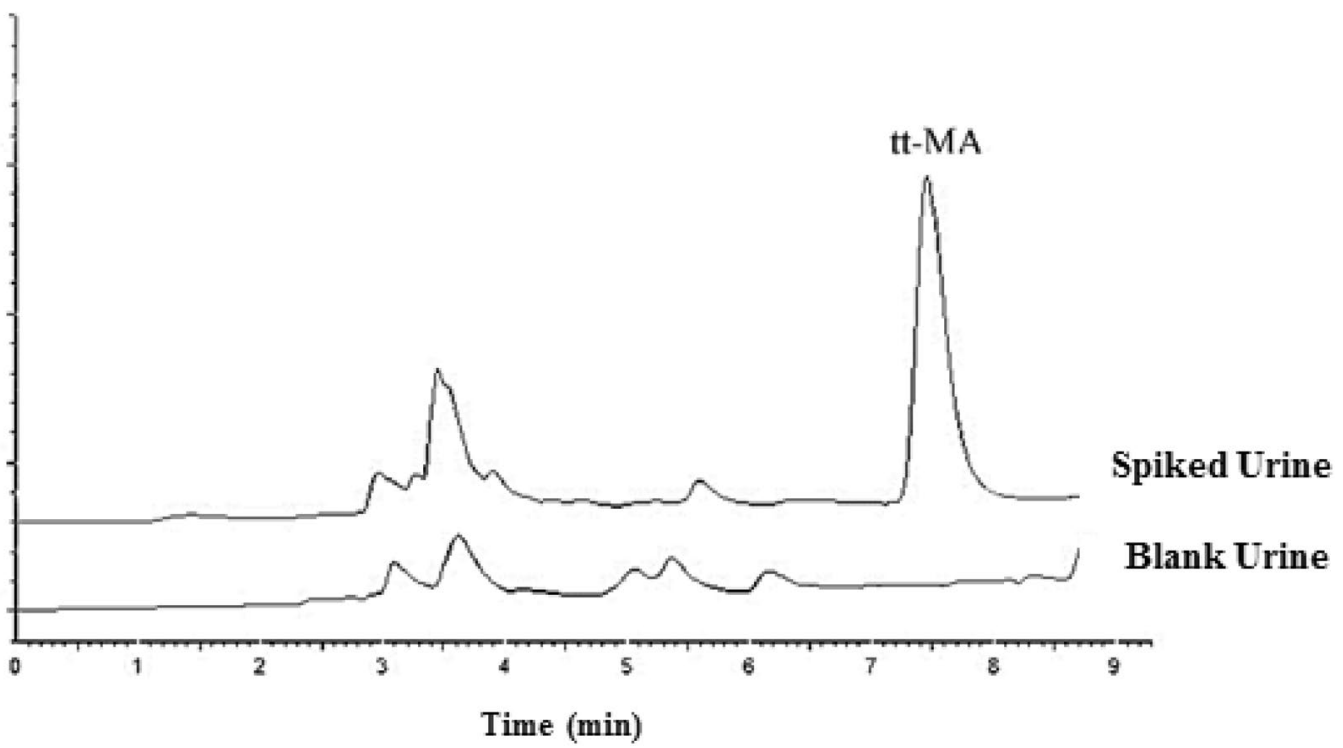

Figure 4. Representative HPLC chromatograms of a real sample from a non-exposed healthy man before (blank) and after spiking with t,t-MA at concentration level of $1 \mu \mathrm{g} / \mathrm{mL}$. (The extraction conditions were as follow: $\mathrm{pH}$ of the sample: 3.0, the volume of extractant solvent: $49.0 \mu \mathrm{L}$, the volume of disperser solvent: $100 \mu \mathrm{L}$, salt amount: $2.0 \mathrm{w} / \mathrm{v} \%$, and extraction time: $2.0 \mathrm{~min}$ ).

\begin{tabular}{|l|l|l|}
\hline \multirow{2}{*}{ Human urine samples } & \multicolumn{2}{|l|}{$\begin{array}{l}\text { t,t-MA level }(\mathrm{mg} / \mathrm{g} \\
\text { creatinine) } \mathbf{M E A N} \pm \mathrm{SD}, \mathbf{N}=\mathbf{3}\end{array}$} \\
\cline { 2 - 3 } & DLLME-SFOD & SPE \\
\hline 1 & $1.20 \pm 0.11$ & $0.99 \pm 0.08$ \\
\hline 2 & $1.46 \pm 0.13$ & $1.70 \pm 0.80$ \\
\hline 3 & $1.64 \pm 0.15$ & $1.11 \pm 0.12$ \\
\hline 4 & $0.81 \pm 0.09$ & $0.97 \pm 0.06$ \\
\hline 5 & $0.54 \pm 0.06$ & $0.65 \pm 0.05$ \\
\hline
\end{tabular}

Table 4. Analysis of urine samples taken from workers of a petrochemical industry using two different extraction technique: DLLME-SFOD and SPE.

Figure 4 presents the chromatograms of a real urine sample collected from unexposed healthy man before and after spiking with $1.0 \mu \mathrm{g} / \mathrm{mL}$ of t,t-MA. As shown in Fig. 4 , no chromatogram was observed at the retention time of target metabolite, indicating acceptable specificity and not require to the additional clean up step to remove interferences before HPLC analysis. As seen in Fig. 4, the analyzed real sample was free from analyte and t,t-MA could be efficiently extracted from urine samples using DLLME-SFOD technique.

Applicability of the optimized method for urine analysis of workers who occupationally exposed to benzene. The optimized procedure was utilized for preconcentration and measurement of $\mathrm{t}, \mathrm{t}-\mathrm{MA}$ in urine samples taken from workers who occupational exposed to benzene in a petrochemical industry. Five end-shift urine specimens were collected from non-smoker employees who were occupationally exposed to benzene. All of urine samples were treated according to the optimized technique of DLLME-SFO, and analysis were performed using HPLC-UV. The results showed that t,t-MA were identified in all of taken samples. The results were expressed as urinary measured $\mathrm{t}, \mathrm{t}-\mathrm{MA}$ to creatinine ( $\mathrm{mg} / \mathrm{g}$ creatinine). The modification of urinary dilution was performed using urinary creatinine because the urinary level of $t, t-M A$ is affected by urine volume. Table 4 presents the findings of the real urine analysis. On the other hand to make another estimation from the accuracy, the results were compared by the solid phase extraction technique (SPE) using SAX cartridge and HPLC-UV detection ${ }^{2}$, which are shown in Table 4 as well. As shown, the present technique is comparable with SPE method as a routine and well-evaluated technique in occupational laboratories.

Comparison of the optimized method with other pretreatment methods. The analytical performance of the proposed method was compared with other previously reported techniques for the extraction and measurement of t,t-MA. As illustrated in Table 5, different solid and liquid phase extraction/ micro extraction procedures have been introduced for monitoring of t,t-MA from urine sample. As seen, the introduced method has an acceptable LOD which is comparable with other analytical techniques used for the measurement 


\begin{tabular}{|c|c|c|c|c|c|c|c|}
\hline Extraction technique & $\begin{array}{l}\text { Organic solvents and } \\
\text { volume }\end{array}$ & Analytical technique & Linear range $\left(\mu \mathrm{g} \mathrm{mL}^{-1}\right)$ & Extraction time (min) & LODs $\left(\mu \mathrm{g} \mathrm{mL}^{-1}\right)$ & RSD $\%$ & References \\
\hline SPE & $\begin{array}{l}\text { sorbic acid: } 50 \mu \mathrm{L} \text { HCL: } \\
900 \mu \mathrm{L} \text { Methanol: } 1 \mathrm{~mL} \\
\text { ammonia: } 1 \mathrm{~mL} \text { ethyl } \\
\text { acetate: } 1 \mathrm{~mL} \text { formic } \\
\text { acid-ethyl acetate: } \\
800 \mu \mathrm{L} \text { methanol and } \\
\text { ortho-phosphoric acid } \\
(2: 98 \mathrm{v} / \mathrm{v}): 90 \mu \mathrm{L}\end{array}$ & HPLC-UV & $0.4-6.8$ & NR & 0.005 & $2-7.1$ & 41 \\
\hline LLE & $\begin{array}{l}\text { HCl:1 mL Diethyl } \\
\text { ether: } 10 \mathrm{~mL} \text { ethereal } \\
\text { diazomethane } 800 \mu \mathrm{L}\end{array}$ & GC-FID & $0.03-1.2$ & NR & 0.02 & 9.7 & 42 \\
\hline MIP- DLLME & $\begin{array}{l}\text { dimethyl sulphoxide } \\
(2 \mathrm{~mL}) \text { ethanol: } 7 \mathrm{~mL} \\
\text { ethanol/acetic acid }(8: 2, \\
\text { v/v): } 4 \text { mL pyridine: } 100 \\
\mu \mathrm{L} \text { trichloroethylene: } \\
80 \mu \mathrm{L} \text { ethyl chlorofor- } \\
\text { mate: } 100 \mu \mathrm{L}\end{array}$ & GC-MS & $0.125-2$ & NR & 0.037 & 5.1 & 43 \\
\hline MIP-MEPS & $\begin{array}{l}\text { Ethanol:300 } \mu \mathrm{L} \text { ethanol- } \\
\text { acetic acid }(80: 20, \mathrm{v} / \mathrm{v}): \\
200 \mu \mathrm{L}\end{array}$ & HPLC-UV & $0.015-2$ & 5 & 0.015 & $3.4-6.6$ & 44 \\
\hline HFLPME & $\begin{array}{l}\text { Different solutions for } \\
\text { condition, washing and } \\
\text { elution steps } 450 \mu \mathrm{L}\end{array}$ & HPLC-UV & $0.005-1.2$ & 120 & 0.001 & $2.7-7.3$ & 45 \\
\hline IP-HF-LPME & Acetone, 1-octanol:24 $\mu \mathrm{L}$ & HPLC-UV & $0.001-0.9$ & 60 & 0.0001 & $2.7-6.1$ & 46 \\
\hline PDLLME & $\begin{array}{l}\text { Chloroform: } 200 \mu \mathrm{L} \text { Tet- } \\
\text { rahydrofuran: } 2000 \mu \mathrm{L}\end{array}$ & HPLC-UV & $0.1-10$ & $<15$ & 0.0001 & $6.3-14$ & 47 \\
\hline DLLME-SFOD & $\begin{array}{l}\text { Matanol:100 } \mu \mathrm{L} \text { 1-unde- } \\
\text { canol: } 49 \mu \mathrm{L}\end{array}$ & HPLC-UV & $0.02-5$ & $<10 \mathrm{~min}$ & 0.006 & $4.3-6.3$ & (Present method) \\
\hline
\end{tabular}

Table 5. Comparison of the SFO-DLLME method with other preconcentration techniques for monitoring of urinary t,t-MA. SPE solid-phase extraction, $L L E$ Liquid-liquid extraction, DLLME dispersive liquid-liquid micro-extraction, MIP-DLLME molecular imprinting polymer-Dispersive liquid liquid microextraction, MIP-MEPS molecular imprinting polymer-micro-extraction by packed sorbent, HFLPME Hallow fiber liquid phase microextraction, IP-HF-LPM Ion-pair-based hollow-fiber liquid-phase microextraction, HPLC highperformance liquid chromatography, PDLLME Partitioned dispersive liquid-liquid microextraction, DLLMESFOD Dispersive liquid liquid microextraction-Solidified organic droplet. NR Not Required.

of $t, t-M A$. Moreover, the very low volume of the used organic extractant solvent with less toxicity in the present method are the major advantages of our suggested method. The proposed technique uses a few microliters of an organic extractant solvent without any other toxic agents such as chlorinated organic solvents. In addition, the extraction process last less than $15 \mathrm{~min}$, which is more rapid than other techniques such as conventional LLE or SPE (>30 min). Although other extraction techniques especially solid phase-based methods have a lower LOD, these techniques require proprietary instruments, expensive SPE cartridges, and complicated steps of sample preparation for the extraction of analyte. These comparisons reveal that the introduced method (DLLMESFOD) is easy, fast, cost effective, and environmentally friendly. Moreover, 1-undecanol is an inexpensive and easily available solvent, which is appropriate for fast extraction of large-scale samples.

Ethics approval. The manuscript has been approved by the ethics committee of Shiraz University of Medical Sciences (Ethical ID: IR.SUMS.REC.1398.1051). No clinical trial was performed in the study but for urine sampling as the experiments involving human participants informed consent have been obtained.

\section{Conclusion}

In the proposed method, a novel, simple, and sensitive DLLME-SFOD method was optimized and validated for the preconcentration and trace measurement of $t, t-M A$ by HPLC-UV in urine sample. In this study, an organic extractant solvent with an appropriate melting point was used; after solidification, it was easily collected. In comparison with other previous techniques, this method enjoys the advantages such as simplicity, low cost, low usage of organic solvent, rapidity, and environmental friendly. In this work, for the first time, DLLME-SFOD was used for the trace determination of t,t-MA in urine samples, which revealed wide linearity, satisfactory relative recovery and good precision. Especially, the LOD of DLLME-SFOD method was $0.006 \mu \mathrm{g} / \mathrm{mL}$, which is lower or comparable with other previous techniques. Furthermore, the most important advantages of this method is that the extraction of $\mathrm{t}, \mathrm{t}$-MA occurs in a short time, which can be used as an efficient method in analytical labs. Because the optimized method does not require any complicated instrument and expensive material, it can be used as a simple protocol for monitoring of employees who occupationally exposed to benzene. 
Received: 30 March 2021; Accepted: 22 July 2021

Published online: 03 August 2021

\section{References}

1. Tolentino, D. et al. Application of statistical models to estimate the correlation between urinary benzene as biological indicator of exposure and air concentrations determined by personal monitoring. AIHA J. 64(5), 625-629 (2003).

2. Scherer, G., Renner, T. \& Meger, M. Analysis and evaluation of trans, trans-muconic acid as a biomarker for benzene exposure. J. Chromatogr. B Biomed. Sci. Appl. 717(1-2), 179-199 (1998).

3. Kamarei, F., Ebrahimzadeh, H. \& Yamini, Y. Optimization of ultrasound-assisted emulsification microextraction with solidification of floating organic droplet followed by high performance liquid chromatography for the analysis of phthalate esters in cosmetic and environmental water samples. Microchem. J. 99(1), 26-33 (2011).

4. Dai, L., Cheng, J., Matsadiq, G., Liu, L. \& Li, J.-K. Dispersive liquid-liquid microextraction based on the solidification of floating organic droplet for the determination of polychlorinated biphenyls in aqueous samples. Anal. Chim. Acta 674(2), 201-205 (2010).

5. Lan, Q. et al. Hematotoxicity in workers exposed to low levels of benzene. Science 306(5702), 1774-1776 (2004).

6. Schnatter, A. R. et al. Peripheral blood effects in benzene-exposed workers. Chem. Biol. Interact. 184(1-2), 174-181 (2010).

7. Katukam, V., Kulakarni, M., Syed, R., Alharbi, K. \& Naik, J. Effect of benzene exposure on fertility of male workers employed in bulk drug industries. Genet. Test. Mol. Biomarkers 16(6), 592-597 (2012).

8. Golbabaei, F., Dehghani, F., Saatchi, M. \& Zakerian, S. A. Evaluation of occupational exposure to different levels of mixed organic solvents and cognitive function in the painting unit of an automotive industry. Health Promot. Perspect. 8(4), 296 (2018).

9. Qu, Q. et al. Validation of biomarkers in humans exposed to benzene: urine metabolites. Am. J. Ind. Med. 37(5), 522-531 (2000).

10. Wiwanitkit, V., Suwansaksri, J. \& Nasuan, P. Urine trans, trans-muconic acid as a biomarker for benzene exposure in gas station attendants in Bangkok, Thailand. Ann. Clin. Lab. Sci. 31(4), 399-401 (2001).

11. Weisel, C. P. Benzene exposure: an overview of monitoring methods and their findings. Chem-Biol Interact. 184(1-2), 58-66 (2010).

12. Zhang, L., Ye, F.-l, Chen, T., Mei, Y. \& Song, S.-Z. Trans, trans-muconic acid as a biomarker of occupational exposure to high-level benzene in China. J. Occup. Environ. Med. 53(10), 1194-8 (2011).

13. Gomes, R. D. P., Sanson, A. L., Lobo, F. A., Afonso, R. J. D. C. F. \& Coutrim, M. X. Method for the determination of benzene metabolite $t$, t-muconic acid in urine by HPLC-UV with an Ion exclusion column. Separations. 3(2), 14 (2016).

14. Wang, X. et al. A novel switchable solvent liquid-phase microextraction technique based on solidification of floating organic droplet: HPLC-FLD analysis of polycyclic aromatic hydrocarbon monohydroxy metabolites in urine samples. New J. Chem. 44(7), 3038-3044 (2020).

15. McNally, K., Sams, C., Loizou, G. \& Jones, K. Evidence for non-linear metabolism at low benzene exposures? A reanalysis of data. Chemico-biol. Interact. 278, 256-268 (2017).

16. Omidi, F., Behbahani, M., Khadem, M., Golbabaei, F. \& Shahtaheri, S. J. Application of a new sample preparation method based on surfactant-assisted dispersive micro solid phase extraction coupled with ultrasonic power for easy and fast simultaneous preconcentration of toluene and xylene biomarkers from human urine samples. J. Iran. Chem. Soc. 16(6), 1131-1138 (2019).

17. Hu, X.-M., Song, S.-Z., Ye, F.-L. \& Liu, L.-W. High-performance liquid chromatographic determination of urinary trans, transmuconic acid excreted by workers occupationally exposed to benzene. Biomed. Environ. Sci. 19(4), 292 (2006).

18. Negri, S., Bono, R., Maestri, L., Ghittori, S. \& Imbriani, M. High-pressure liquid chromatographic-mass spectrometric determination of sorbic acid in urine: verification of formation of trans, trans-muconic acid. Chem. Biol. Interact. 153, 243-246 (2005).

19. Abbaszadeh, S., Yousefinejad, S., Jafari, S. \& Soleimani, E. In-syringe ionic liquid-dispersive liquid liquid microextraction coupled with HPLC for thedetermination of trans, trans-muconic acid in human urine sample. J. Sep. Sci. (2021). https://doi.org/10.1002/ jssc. 202100044

20. Omidi, F., Khadem, M., Dehghani, F., Seyedsomeah, M. \& Shahtaheri, S. J. Ultrasound-assisted dispersive micro-solid-phase extraction based on $\mathrm{N}$-doped mesoporous carbon and high-performance liquid chromatographic determination of 1-hydroxypyrene in urine samples. J. Sep. Sci. 43(13), 2602-2609 (2020).

21. Vela-Soria, F. et al. HPLC-MS/MS method for the determination of perfluoroalkyl substances in breast milk by combining saltassisted and dispersive liquid-liquid microextraction. Anal. Bioanal. Chem. 412(28), 7913-7923 (2020).

22. Mansour, F. R. \& Danielson, N. D. Solidification of floating organic droplet in dispersive liquid-liquid microextraction as a green analytical tool. Talanta 170, 22-35 (2017).

23. Zhou, Y. et al. Dispersive liquid-liquid microextraction based on the solidification of a floating organic droplet for simultaneous analysis of diethofencarb and pyrimethanil in apple pulp and peel. Anal. Bioanal. Chem. 399(5), 1901-1906 (2011).

24. Silva, L. K. et al. Solidified floating organic drop microextraction (SFODME) for the simultaneous analysis of three non-steroidal anti-inflammatory drugs in aqueous samples by HPLC. Anal. Bioanal. Chem. 698, 1-9 (2021).

25. Gao, M. et al. An effervescence-assisted switchable fatty acid-based microextraction with solidification of floating organic droplet for determination of fluoroquinolones and tetracyclines in seawater, sediment, and seafood. Anal. Bioanal. Chem. 410(11), 2671-2687 (2018).

26. Kousha, M., Tavakoli, S., Daneshvar, E., Vazirzadeh, A. \& Bhatnagar, A. Central composite design optimization of Acid Blue 25 dye biosorption using shrimp shell biomass. J. Mol. Liq. 207, 266-273 (2015).

27. Asfaram, A., Ghaedi, M., Agarwal, S., Tyagi, I. \& Gupta, V. K. Removal of basic dye Auramine-O by ZnS: Cu nanoparticles loaded on activated carbon: optimization of parameters using response surface methodology with central composite design. RSC Adv. 5(24), 18438-18450 (2015)

28. Toudeshki, R. M., Dadfarnia, S. \& Shabani, A. M. H. Surface molecularly imprinted polymer on magnetic multi-walled carbon nanotubes for selective recognition and preconcentration of metformin in biological fluids prior to its sensitive chemiluminescence determination: central composite design optimization. Anal. Chim. Acta 1089, 78-89 (2019).

29. Heravizadeh, O. R., Khadem, M., Nabizadeh, R. \& Shahtaheri, S. J. Synthesis of molecularly imprinted nanoparticles for selective exposure assessment of permethrin: optimization by response surface methodology. J. Environ. Health Sci. Eng. 17(1), 393-406 (2019).

30. Heravizadeh, O. R., Khadem, M., Dehghani, F. \& Shahtaheri, S. J. Determination of fenthion in urine samples using molecularly imprinted nanoparticles: modelling and optimisation by response surface methodology. Int. J. Environ. Anal. Chem. 6111, 1-15 (2020).

31. Shukri, D. S. M., Sanagi, M. M., Ibrahim, W. A. W., Abidin, N. N. Z. \& Aboul-Enein, H. Y. Liquid chromatographic determination of NSAIDs in urine after dispersive liquid-liquid microextraction based on solidification of floating organic droplets. Chromatographia 78(15-16), 987-994 (2015).

32. Taheri, S., Jalali, F., Fattahi, N., Jalili, R. \& Bahrami, G. Sensitive determination of methadone in human serum and urine by dispersive liquid-liquid microextraction based on the solidification of a floating organic droplet followed by HPLC-UV. J. Sep. Sci. 38(20), 3545-3551 (2015).

33. Nikaeen, G., Yousefinejad, S., Rahmdel, S., Samari, F. \& Mahdavinia, S. Central composite design for optimizing the biosynthesis of silver nanoparticles using plantago major extract and investigating antibacterial, antifungal and antioxidant activity. Sci. Rep. 10(1), 1-16 (2020). 
34. Sarrai, A. E. et al. Using central composite experimental design to optimize the degradation of tylosin from aqueous solution by photo-fenton reaction. Materials. 9(6), 428 (2016).

35. Zhang, K., Li, S., Wang, Y., Fan, J. \& Zhu, G. Air-assisted liquid-liquid microextraction based on solidification of floating deep eutectic solvent for the analysis of ultraviolet filters in water samples by high performance liquid chromatography with the aid of response surface methodology. J. Chromatogr. A. 1618, 460876 (2020).

36. Ramezani, A. M., Yousefinejad, S., Nazifi, M. \& Absalan, G. Response surface approach for isocratic separation of some natural anthraquinone dyes by micellar liquid chromatography. J. Mol. Liq. 242, 1058-1065 (2017).

37. Nekoeinia, M., Yousefinejad, S. \& Abdollahi-Dezaki, A. Prediction of E TN polarity scale of ionic liquids using a QSPR approach. Ind. Eng. Chem. Res. 54(50), 12682-12689 (2015).

38. Zheng, C., Zhao, J., Bao, P., Gao, J. \& He, J. Dispersive liquid-liquid microextraction based on solidification of floating organic droplet followed by high-performance liquid chromatography with ultraviolet detection and liquid chromatography-tandem mass spectrometry for the determination of triclosan and 2, 4-dichlorophenol in water samples. J. Chromatogr. A 1218(25), 3830-3836 (2011).

39. Canales, R., Guiñez, M., Bazán, C., Reta, M. \& Cerutti, S. Determining heterocyclic aromatic amines in aqueous samples: a novel dispersive liquid-liquid micro-extraction method based on solidification of floating organic drop and ultrasound assisted back extraction followed by UPLC-MS/MS. Talanta 174, 548-555 (2017).

40. Tajik, S. \& Taher, M. A. New method for microextraction of ultra trace quantities of gold in real samples using ultrasound-assisted emulsification of solidified floating organic drops. Microchim. Acta 173(1-2), 249-257 (2011).

41. Lee, B. L., Ong, H. Y., Ong, Y. B. \& Ong, C. N. A sensitive liquid chromatographic method for the spectrophotometric determination of urinary trans, trans-muconic acid. J. Chromatogr. B 818(2), 277-283 (2005).

42. Bartczak, A. et al. Evaluation of assays for the identification and quantitation of muconic acid, a benzene metabolite in human urine. J. Toxicol. Environ. Health Part A 42(3), 245-258 (1994).

43. Mudiam, M. K. R. et al. Determination of $\mathrm{t}, \mathrm{t}$-muconic acid in urine samples using a molecular imprinted polymer combined with simultaneous ethyl chloroformate derivatization and pre-concentration by dispersive liquid-liquid microextraction. Anal. Bioanal. Chem. 405(1), 341-349 (2013).

44. Soleimani, E., Bahrami, A., Afkhami, A. \& Shahna, F. G. Determination of urinary trans, trans-muconic acid using molecularly imprinted polymer in microextraction by packed sorbent followed by liquid chromatography with ultraviolet detection. J. Chromatogr. B 1061, 65-71 (2017).

45. Ghamari, F., Bahrami, A., Yamini, Y., Shahna, F. G. \& Moghimbeigi, A. Development of hollow-fiber liquid-phase microextraction method for determination of urinary trans, trans-muconic acid as a biomarker of benzene exposure. Anal. Chem. Insights. 11, S40177 (2016)

46. Bahrami, A., Ghamari, F., Yamini, Y., Ghorbani Shahna, F. \& Koolivand, A. Ion-pair-based hollow-fiber liquid-phase microextraction combined with high-performance liquid chromatography for the simultaneous determination of urinary benzene, toluene, and styrene metabolites. J. Sep. Sci. 41(2), 501-508 (2018).

47. Rismanchian, M., Ebrahim, K. \& Ordudari, Z. Development of a simple and rapid method for determination of trans, transMuconic Acid in human urine using PDLLME preconcentration and HPLC-UV detection. Chem. Pap. 73(10), 2485-2492 (2019).

\section{Acknowledgements}

This work was supported financially by the Shiraz University of Medical Sciences (SUMS), Shiraz, Iran (Grant No. 98-01-42-20778; S. Yousefinejad). The authors thanks SUMS for their help.

\section{Author contributions}

S.Y. was the supervisor of team in all research steps including data gathering, data analysis, and manuscript preparation/revision. S.Y. also prepared Tables and Figs related to optimization using CCD and real samples. F.D. had main contribution in the experimental data gathering (optimization and analytical detemination), preparation of results and data analysis. F.O. and O.H. contributed in conducting some results especially in real samples and writing some parts of manuscript. F.D. and S.Y. wrote the main manuscript text and all authors had contribution in correction and revision of the final version.

\section{Competing interests}

The authors declare no competing interests.

\section{Additional information}

Supplementary Information The online version contains supplementary material available at https://doi.org/ 10.1038/s41598-021-95174-5.

Correspondence and requests for materials should be addressed to S.Y.

Reprints and permissions information is available at www.nature.com/reprints.

Publisher's note Springer Nature remains neutral with regard to jurisdictional claims in published maps and institutional affiliations.

Open Access This article is licensed under a Creative Commons Attribution 4.0 International License, which permits use, sharing, adaptation, distribution and reproduction in any medium or format, as long as you give appropriate credit to the original author(s) and the source, provide a link to the Creative Commons licence, and indicate if changes were made. The images or other third party material in this article are included in the article's Creative Commons licence, unless indicated otherwise in a credit line to the material. If material is not included in the article's Creative Commons licence and your intended use is not permitted by statutory regulation or exceeds the permitted use, you will need to obtain permission directly from the copyright holder. To view a copy of this licence, visit http://creativecommons.org/licenses/by/4.0/.

(C) The Author(s) 2021 